\title{
QUALIDADE DO SOLO AVALIADA PELO "SOIL QUALITY KIT TEST" EM DOIS EXPERIMENTOS DE LONGA DURAÇÃO NO RIO GRANDE DO SUL ${ }^{(1)}$
}

\author{
Telmo Jorge Carneiro Amado ${ }^{(2)}$, Paulo Cesar Conceição ${ }^{(3)}$, Cimélio \\ Bayer $^{(4)}$ \& Flávio Luiz Foletto Eltz ${ }^{(5)}$
}

\begin{abstract}
RESUMO
A avaliação da qualidade do solo (QS) é importante estratégia no planejamento agrícola, possibilitando a identificação e o aprimoramento de sistemas de manejo com características de alta produtividade e de preservação ambiental. $\mathrm{O}$ presente estudo foi realizado em dois experimentos de longa duração (10 e 15 anos) conduzidos no Sul do Brasil e teve por objetivo avaliar o efeito de sistemas de manejo na QS, utilizando um kit de análise expedita de qualidade de solo (KQS), desenvolvido pelo Instituto de Qualidade do Solo-USDA-ARS. A eficiência desse kit foi avaliada pela comparação com os métodos tradicionais utilizados na ciência do solo. Nas duas áreas experimentais investigou-se um total de 12 tratamentos, os quais englobaram sistemas de preparo com diferentes intensidades de revolvimento do solo (preparo convencional, preparo reduzido e plantio direto) e sistemas de culturas com ampla faixa de adição de resíduos vegetais ao solo, além da aplicação de doses anuais de N-uréia, variando de 0 a $144 \mathrm{~kg} \mathrm{ha}^{-1}$. Em cada base experimental uma área sob campo natural foi avaliada, servindo como referência da condição do solo na ausência de interferência antrópica. Como indicadores de QS, foram avaliados infiltração de água, respiração do solo, densidade do solo, teor de nitrato+nitrito $\left(\mathrm{N}_{-} \mathrm{NO}_{3}^{-}+\mathrm{N}-\mathrm{NO}_{2}{ }^{-}\right)$, estabilidade de agregados em água e $\mathrm{pH}$. De maneira geral, os coeficientes de correlação entre os métodos do KQS e os métodos tradicionais foram elevados, sendo o mais alto para o indicador $\mathrm{pH}(\mathrm{r}=\mathbf{0 , 9 8 )}$ e o menor para o indicador infiltração de água no solo $(\mathrm{r}=0,42)$. Os tratamentos
\end{abstract}

\footnotetext{
(1) Parte da Tese de Mestrado do segundo autor apresentada ao Programa de Pós-Graduação em Agronomia, Universidade Federal de Santa Maria - UFSM. Recebido para publicação em agosto de 2005 e aprovado em dezembro de 2006.

(2) Professor Associado do Departamento de Solos, Universidade Federal de Santa Maria - UFSM. Campus Universitário, CEP 97105-900 Santa Maria (RS). Bolsista do CNPq. E-mail: tamado@smail.ufsm.br

(3) Doutor em Ciência do Solo, PPG em Ciência do Solo, Universidade Federal do Rio Grande do Sul - UFRGS. Av. Bento Gonçalves 7712 CEP 97105-400 Porto Alegre (RS). E-mail: pcconceicao@hotmail.com

(4) Professor Adjunto do Departamento de Solos, UFRGS. Bolsista do CNPq. E-mail: cimelio.bayer@ufrgs.br

(5) Professor Titular do Departamento de Solos, UFSM. Bolsista do CNPq. E-mail: feltz@ccr.ufsm.br
} 
selecionados foram teoricamente ordenados em ordem crescente de QS, a qual foi reproduzida de forma eficiente pelo índice de estoque de carbono (IEC), calculado pela razão entre o estoque de C orgânico do solo, na camada de 0-5 cm, de cada tratamento e o estoque de $\mathrm{C}$ orgânico no solo sob campo natural. Os indicadores estabilidade de agregados, $\mathrm{N}-\mathrm{NO}_{3}{ }^{-}+\mathrm{N}-\mathrm{NO}_{2}{ }^{-}$e respiração do solo foram os mais eficientes em discriminar a QS. O KQS foi eficiente em avaliar a QS dos tratamentos nas duas áreas experimentais. Os níveis mais elevados de QS foram alcançados nos tratamentos com plantio direto e consórcio de gramíneas e leguminosas tropicais, devido à cobertura do solo e às elevadas adições de $\mathrm{C}$ e $\mathrm{N}$ via resíduos culturais.

Termos de indexação: conservação do solo, culturas de cobertura, indicadores de qualidade do solo, sistemas de manejo do solo.

\title{
SUMMARY: SOIL QUALITY EVALUATED BY “SOIL QUALITY KIT" IN TWO LONG-TERM SOIL MANAGEMENT EXPERIMENTS IN RIO GRANDE DO SUL STATE, BRAZIL
}

\begin{abstract}
The soil quality (SQ) evaluation is an important part of agricultural planning. It allows the identification and improvement of high-yielding management systems with characteristics of environment preservation. This study was carried out in two long-term soil management experiments (10 and 15 years) in Rio Grande do Sul State, Brazil. The main objective of this study was to evaluate the effectiveness of the Soil Quality Kit (SQK) developed by the Soil Quality Institute - ARS -USDA, compared to traditional soil science methods. Twelve treatments of cropping and tillage systems in a range of different tillage intensities, biomass input amounts and urea- $N$ fertilization (0 to $144 \mathrm{~kg} \mathrm{ha}^{-1}$ ) were evaluated. A native vegetation field close to each experimental area was sampled as reference treatment. The following $S Q$ indicators: water infiltration, soil respiration, soil density, $\mathrm{N}-\mathrm{NO}_{3}{ }^{-}+\mathrm{N}-\mathrm{NO}_{2}$, water aggregate stability and $\mathrm{pH}$ were evaluated. The correlation between the $S Q K$ and soil science methods was generally high. The highest correlation was observed with $\mathrm{pH}(r=0.98)$ and the lowest for infiltration $(r=0.42)$. The soil management treatments were theoretically classified by crescent $S Q$ order. The carbon pool index $(C P I)$ was obtained dividing soil organic carbon stock of each treatment by native vegetation soil organic carbon 0 to $5 \mathrm{~cm}$ deep. The CPI reproduces the SQ classification efficiently. Aggregate stability, soil respiration and $\mathrm{N}-\mathrm{NO}_{3}{ }^{-}+\mathrm{N}-\mathrm{NO}_{2}-$ were the most efficient indicators at discriminating SQ. The Soil Quality Test Kit was an efficient tool to evaluate the soil quality in both experimental areas. Highest soil quality levels were achieved under notillage with a grass - tropical legume consortium, which provides soil cover and high carbon and nitrogen addition through crop residues.
\end{abstract}

Index terms: Soil conservation, soil quality indicators, soil tillage systems, cover crops.

\section{INTRODUÇÃO}

A agricultura brasileira apresentou, na última década, expressivos incrementos de rendimento e de produção, notadamente nas culturas de grãos. Para que esses avanços sejam mantidos em longo prazo fazse necessário monitorar a qualidade do solo agrícola. O nível de alteração na qualidade do solo (QS) pode ser avaliado pela mensuração do estado atual de determinadas propriedades e comparação deste com o estado natural do solo, sem interferência antrópica, ou com valores que são considerados ideais (Doran \& Parkin, 1994; Sarrantonio et al., 1996). Nesse caso, as dificuldades residem em selecionar quais propriedades serão avaliadas e definir os valores considerados adequados ou ideais, os quais podem ser variáveis de acordo com a classe de solo investigada (Arshad \& Martin, 2002). Além disso, alguns anos são necessários para se verificar a resposta das propriedades do solo às alterações do sistema de manejo. Dessa forma, preferencialmente, a QS deve ser avaliada em experimentos ou áreas agrícolas com histórico de manejo de longa duração (Motta et al., 2000).

A necessidade de diagnóstico rápido e confiável da QS conduziu o Instituto de Qualidade do Solo, vinculado ao Serviço de Pesquisa Agrícola do Departamento de Agricultura dos Estados Unidos, a desenvolver um kit de qualidade do solo (KQS) (USDA- 
ARS, 1998). Informações detalhadas sobre este KQS podem ser obtidas na página http://soils.usda.gov/sqi/ assessment/test_kit.html (acessado em 12/9/2006).

O KQS possibilita avaliar, entre outros, os seguintes indicadores: infiltração de água, respiração do solo, estabilidade de agregados em água, $\mathrm{pH}$, densidade do solo, teor de $\mathrm{N}-\mathrm{NO}_{3}{ }^{-}+\mathrm{N}-\mathrm{NO}_{2}{ }^{-}$, condutividade elétrica e presença de minhocas (USDAARS, 1998). Esse KQS foi testado em mais de 50 locais dos Estados Unidos e em diversos outros países (Sarrantonio et al., 1996; Ditzler \& Tugel, 2002), apresentando elevada correlação com os métodos tradicionais da ciência do solo (Liebig et al., 1996). O KQS caracteriza-se pela simplicidade e praticidade dos métodos utilizados, embora, para alguns indicadores, exista dúvida quanto à sua eficácia. No Brasil, ainda são escassas as informações a respeito dessa ferramenta. Com isso, os objetivos do presente trabalho foram avaliar o desempenho do KQS em acessar a QS e identificar as práticas de manejo, em dois experimentos de manejo do solo no Rio Grande do Sul (RS), que permitam alcançar QS.

\section{MATERIAL E MÉTODOS}

\section{Áreas experimentais}

Dois experimentos de longa duração em manejo do solo, ambos localizados na Depressão Central do RS, foram avaliados neste trabalho. O primeiro foi conduzido na Universidade Federal de Santa Maria (UFSM) há 10 anos, e o segundo, na Universidade Federal do Rio Grande do Sul (UFRGS) há 15 anos. As áreas experimentais distam entre si aproximadamente $250 \mathrm{~km}$.

Em Santa Maria (RS), o solo é classificado como Argissolo Vermelho distrófico arênico A moderado textura franco-arenosa (Embrapa, 1999) com $87 \mathrm{~g} \mathrm{~kg}^{-1}$ de argila, a seguir denominado de PVd arênico. A localização geográfica é $29^{\circ} 45^{\prime}$ de latitude sul e $53^{\circ} 42$ ' de longitude oeste, com altitude de $96 \mathrm{~m}$. O clima da região é subtropical de verão úmido, Cfa, segundo classificação climática de Köppen. A precipitação média anualé de 1.769 mm (Moreno, 1961).

As parcelas utilizadas, com dimensões de $3,5 \times 22 \mathrm{~m}$, fazem parte de um experimento de perdas de solo e água sob chuva natural, em delineamento completamente casualizado com duas repetições. Os tratamentos selecionados foram os seguintes: (1) solo descoberto (DESC.); (2) pousio/milho (Zea mays L.) sob plantio direto (PD P/M); (3) azevém (Lolium multiflorum Lam.) + ervilhaca (Vicia sativa (L.) Walp.)/milho sob plantio direto (PD Az/M); (4) milho+mucuna (Stizolobium cinereum Piper \& Tracy) sob plantio direto (PD M+Muc); e (5) campo natural (CN). Em todos os anos, a semeadura das culturas de cobertura de inverno foi realizada no mês de abril, e a da cultura do milho, nos meses de outubro ou novembro. A cultura da mucuna foi implantada no mês de janeiro, intercalar ao milho. Os tratos culturais seguiram as recomendações técnicas da cultura do milho (Programa..., 1999). As culturas de milho e mucuna foram implantadas com semeadora manual (saraquá), e as de azevém + ervilhaca, mediante abertura de sulcos superficiais com enxada e espaçadas de $15 \mathrm{~cm}$ entre linhas. Portanto, todas as culturas foram implantadas seguindo os princípios do sistema plantio direto. A adubação nitrogenada no milho foi de $130 \mathrm{~kg} \mathrm{ha}^{-1}$ nos tratamentos PD P/M e $\mathrm{PD}$ Az/M e de $65 \mathrm{~kg} \mathrm{ha}^{-1}$ no tratamento PD M+Muc. Com exceção do CN, os demais tratamentos receberam a mesma adubação com $\mathrm{PeK}$, seguindo recomendações da Comissão de Fertilidade do Solo-RS/SC (1995). Na implantação do experimento (1991) foram aplicados aproximadamente $3,5 \mathrm{Mg}^{-1}{ }^{-1}$ de calcário dolomítico incorporado ao solo, com arado de disco, a uma profundidade de $20 \mathrm{~cm}$. Em 1996 foi realizada uma reaplicação do mesmo corretivo, distribuído uniformemente na superfície do solo, na dose de $2 \mathrm{Mg} \mathrm{ha}^{-1}$. Detalhes referentes à condução do experimento foram descritos em Debarba \& Amado (1997).

A Estação Experimental Agronômica da UFRGS, em Eldorado do Sul (RS), onde está localizado o segundo experimento, possui solo classificado como Argissolo Vermelho distrófico típico A moderado textura francoargilo-arenosa (Embrapa, 1999), com $220 \mathrm{~g} \mathrm{~kg}^{-1} \mathrm{de}$ argila, a seguir denominado de PVd típico. A localização geográfica é: $30^{\circ} 06^{\prime}$ de latitude sul e $51^{\circ} 40$ ' de longitude oeste, com altitude de $96 \mathrm{~m}$. O clima da região é o subtropical de verão úmido, Cfa, segundo classificação climática de Köppen. A precipitação média anual é de $1.440 \mathrm{~mm}$ (Moreno, 1961).

Nessa área experimental foram avaliados sistemas de preparo do solo e sistemas de cultura, com doses de adubação nitrogenada. As parcelas mediram 5 x 10 m, em blocos ao acaso com três repetições. Sete tratamentos foram selecionados: (1) aveia-preta (Avena strigosa Schreber)/milho sob preparo convencional e sem adubação nitrogenada (PC A/M $0 \mathrm{~N})$; (2) aveia-preta/milho sob preparo convencional (PC A/M); (3) aveia-preta/milho sob preparo reduzido (PR A/M); (4) aveia-preta/milho sob plantio direto (PD A/M); (5) aveia-preta + ervilhaca/milho + caupi (Vigna unguiculata (L.) Walp.) sob plantio direto (PD A+V/M+C); (6) milho + guandu (Cajanus cajans (L.) Millsp) sob plantio direto (PD M+G); e (7) campo natural $(\mathrm{CN})$. As culturas de cobertura de inverno foram implantadas nos meses de abril ou maio, e a do milho, nos meses de setembro ou outubro. As culturas estivais de cobertura do solo (guandu e caupi) foram implantadas intercalares ao milho no período de floração plena da cultura principal. Até o quinto ano a implantação das culturas de inverno foi realizada a lanço, e a do milho, com saraquá. Após esse período, a implantação das culturas foi feita com semeadora de tração mecânica, com exceção do guandu e do caupi, que foram implantados com saraquá. A adubação 
nitrogenada, na dose média de $144 \mathrm{~kg} \mathrm{ha}^{-1}$, para os 15 anos de condução do experimento, foi aplicada em todos os tratamentos com milho, exceto o PC A/M 0N. Com exceção do $\mathrm{CN}$, que não recebeu adubação e calagem, os demais tratamentos receberam adubação com $\mathrm{P}$ e $\mathrm{K}$ na cultura do milho, conforme as recomendações da Comissão de Fertilidade do SoloRS/SC (1995). A calagem foi realizada superficialmente, na dose de $2 \mathrm{Mg} \mathrm{ha}^{-1}$ de calcário dolomítico, aplicada a cada quatro anos, conforme a necessidade determinada por análises de solo. No tratamento $\mathrm{PD} \mathrm{M}+\mathrm{G}$ somente uma calagem foi realizada no período. As operações de preparo do solo foram feitas antecedendo a cultura do milho. No preparo convencional, o resíduo foi incorporado mediante uma aração com arado de discos e duas gradagens. No preparo reduzido, foi utilizado um escarificador de hastes, incorporando parcialmente os resíduos ao solo. No sistema plantio direto, o solo somente foi mobilizado na linha de semeadura pela semeadora equipada com duplo disco. Detalhes deste experimento encontramse em Lovato (2001).

\section{Ordenação teórica dos tratamentos quanto à qualidade do solo}

Os tratamentos, em ambas as áreas experimentais, foram ordenados com base nos pressupostos de manejo para melhorar a QS, quais sejam mínima mobilização do solo, permanente cobertura do solo e elevada adição de resíduos culturais ricos em C e N (Vezzani, 2001; Mielniczuk et al., 2003). Detalhes que dão suporte teórico a essa ordenação são apresentados em Conceição et al. (2005). A ordem hierárquica crescente de QS foi a seguinte: DESC. < PD P/M $<\mathrm{PD} \mathrm{Az/}$ $\mathrm{M}<\mathrm{PD} \mathrm{M}+\mathrm{Muc}$, no $\mathrm{PVd}$ arênico, e $\mathrm{PC} \mathrm{A} / \mathrm{M} 0 \mathrm{~N}<\mathrm{PC} \mathrm{A} /$
$\mathrm{M}<$ PR A/M $<$ PD A/M $<$ PD A + V/M + C $<$ PD M+G, no $\mathrm{PVd}$ típico. Em ambas as áreas, o $\mathrm{CN}$ não foi enquadrado em uma ordem hierárquica específica, sendo a referência de qualidade do solo sem a interferência antrópica.

\section{Comparação do KQS com os métodos tradicionais da ciência do solo}

Foram avaliados a campo seis indicadores (infiltração de água, respiração do solo, estabilidade de agregados, densidade do solo, $\mathrm{pH}$ e nitrato + nitrito), usando o KQS, posteriormente à colheita da cultura econômica (milho). Os mesmos indicadores também foram avaliados com os métodos tradicionalmente utilizados na ciência do solo (Page, 1982; Klute, 1986; Embrapa, 1997). Os indicadores estabilidade de agregados, $\mathrm{pH}$ e nitrato + nitrito foram avaliados com uma repetição por parcela, e os indicadores infiltração de água, respiração e densidade do solo, com duas repetições.

Para avaliação da infiltração de água pelo KQS, utilizaram-se cilindros de $15 \mathrm{~cm}$ de diâmetro e $12,5 \mathrm{~cm}$ de altura, introduzidos no solo a uma profundidade de $7,5 \mathrm{~cm}$. Na parte interna do cilindro colocou-se um filme de polietileno sobre o solo, para controlar o início da infiltração. Após terem sido adicionados $444 \mathrm{~mL}$ de água, o filme de polietileno foi retirado e anotado o tempo transcorrido para a infiltração do volume de água. Uma segunda avaliação da infiltração, seguindo o mesmo procedimento descrito anteriormente, porém em outro local da parcela, foi efetuada. O método usual da ciência do solo para fins de comparação foi o de duplos anéis concêntricos, descrito por Bouwer (1986). As taxas de infiltração foram interpretadas conforme o quadro 1.

Quadro 1. Classificação das propriedades do solo conforme proposto pelo kit de qualidade do solo

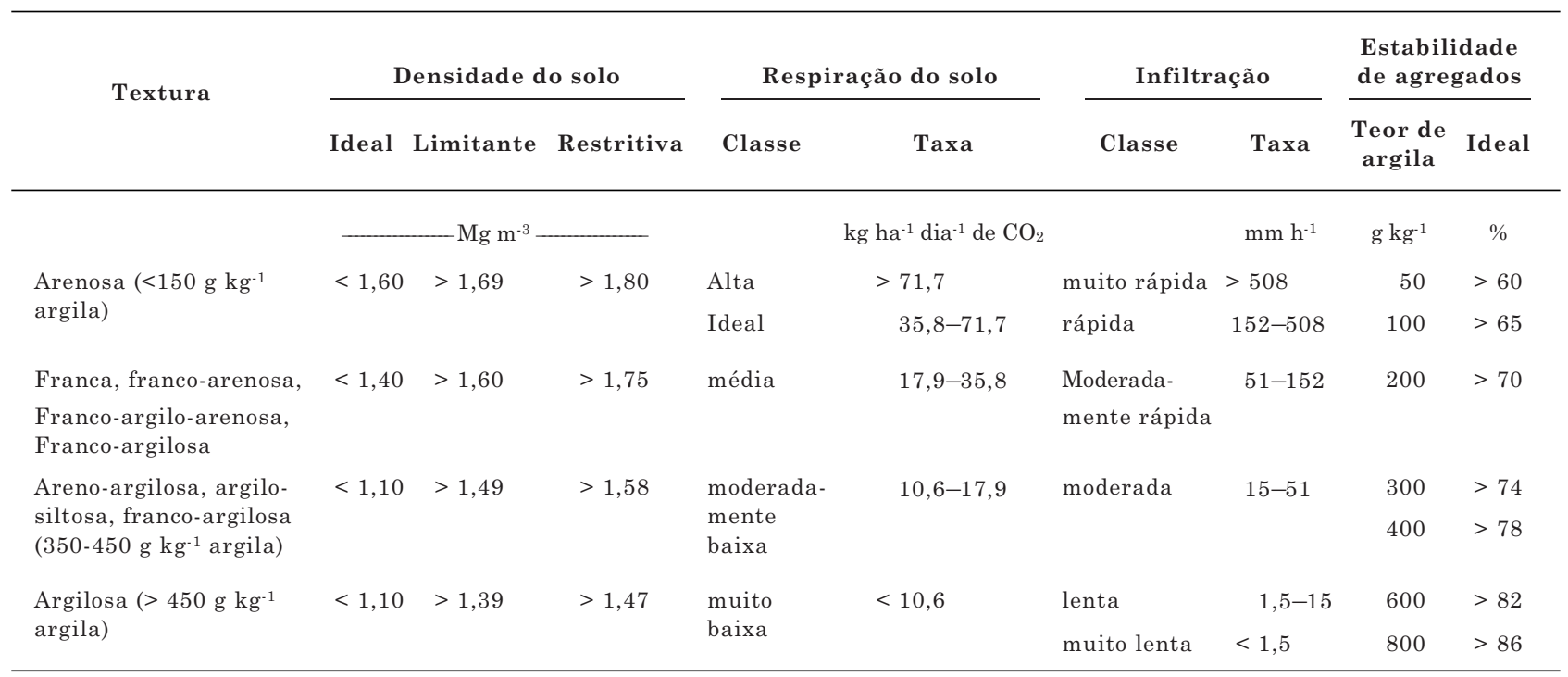

Os indicadores pH e nitrato+nitrito não possuem uma classificação específica. O pH na faixa de 5,5 a 7,0 é considerado ideal. Fonte: Adaptado do Soil Quality Kit Test Guide (USDA-ARS, 1998). 
O método do KQS para avaliação da respiração do solo consistiu em captar o $\mathrm{CO}_{2}$ proveniente da atividade biológica do solo, medindo-o por meio de colorimetria. Para isso, foram utilizados os mesmos cilindros anteriores, sendo as leituras realizadas $24 \mathrm{~h}$ após a determinação da infiltração, para permitir a drenagem da água dos macroporos, aproximando-se da capacidade de campo. Então, os cilindros foram fechados com uma tampa com três orifícios, vedados com borracha. Após $30 \mathrm{~min}$, no orifício central foi colocado um termômetro digital introduzido a uma profundidade de $3 \mathrm{~cm}$ no solo. Nos outros dois orifícios foram introduzidas duas agulhas simultaneamente, uma em cada orifício. Uma das agulhas permitiu o fluxo interno de ar, e através da outra, conectada a um tubo medidor de $\mathrm{CO}_{2}$ acoplado a uma seringa, procedeu-se à sucção de $100 \mathrm{~cm}^{3}$ de ar do interior da câmara. A leitura foi efetuada mediante a mudança de coloração no medidor de $\mathrm{CO}_{2}$, seguindo graduação existente no próprio tubo. $\mathrm{O}$ método-padrão usado na comparação foi o descrito por Anderson (1986), com captação do $\mathrm{CO}_{2}$ em solução de $\mathrm{NaOH}$ e titulação com $\mathrm{HCl}$.

A densidade do solo, pelo método do KQS, foi feita coletando-se solo com estrutura preservada, com um cilindro de $7,5 \mathrm{~cm}$ de diâmetro e $12,5 \mathrm{~cm}$ de altura, introduzido no solo até aproximadamente $7,5 \mathrm{~cm}$ de profundidade. A altura internamente, do solo até a borda superior do cilindro, foi registrada visando ao cálculo do volume de solo amostrado. Após a remoção do cilindro, a borda inferior com solo foi nivelada com espátula e, cuidadosamente, todo o solo do cilindro foi transferido para embalagem plástica. Uma amostra de solo com estrutura alterada foi seca em forno de microondas, em dois ciclos de quatro minutos cada, na potência máxima, sendo posteriormente pesada em balança de precisão, para determinação da massa. A densidade foi obtida dividindo-se o valor de massa do solo seco pelo volume ocupado no cilindro. O métodopadrão utilizado para comparação foi o do anel volumétrico, descrito em Embrapa (1997).

Para determinação da estabilidade de agregados em água, utilizaram-se amostras coletadas da camada de $0-7,5 \mathrm{~cm}$, secas ao ar e passadas em peneira de $2 \mathrm{~mm}$. Dez gramas de agregados $<2 \mathrm{~mm}$ foram colocados em peneira de $0,25 \mathrm{~mm}$, sobre um pano úmido, com a finalidade de umedecer lentamente os agregados. Após cinco minutos, as peneiras com as amostras foram manualmente agitadas em um recipiente com água, com 30 oscilações por minuto, durante três minutos. Posteriormente, o conjunto solo-peneira foi colocado sobre um pano seco, para retirada do excesso de umidade, e levado para secagem através da passagem de ar quente oriundo de um secador de ar portátil. As amostras secas foram pesadas (peso dos agregados mais partículas maiores que $0,25 \mathrm{~mm}$ ), colocadas em solução dispersante de calgon (uma colher de sopa, resultando em uma concentração de aproximadamente $20 \mathrm{~g} \mathrm{~L}^{-1}$ ) durante cinco minutos, lavadas e, novamente, secas e pesadas, para determinação das partículas individuais. $\mathrm{O}$ método-padrão foi o descrito por Kemper \& Rosenau (1986), o qual utiliza amostra de agregados com tamanho de 1-2 mm.

Para determinação do $\mathrm{pH}$, segundo o método do KQS, aproximadamente $30 \mathrm{~g}$ de solo seco ao ar, provenientes das amostras coletadas na profundidade de $0-7,5 \mathrm{~cm}$, foram colocados em um recipiente plástico e a este adicionado uma colher-medida de água com volume aproximado de $30 \mathrm{~mL}$, resultando em uma relação solo-extrator de 1:1. O recipiente foi tampado e agitado, manualmente, por 25 vezes, aguardando-se 15 min para a estabilização da suspensão. Os resultados foram obtidos pela leitura direta em um peagâmetro portátil. Para fins de comparação, foi utilizado o método descrito em Embrapa (1997).

$\mathrm{Na}$ determinação do teor de $\mathrm{N}-\mathrm{NO}_{3}{ }^{-}+\mathrm{N}^{-} \mathrm{NO}_{2}{ }^{-}$ utilizou-se a mesma solução de solo preparada para a leitura do pH. Essa solução foi filtrada com papel poroso. Posteriormente, retiraram-se algumas gotas, que foram colocadas sobre a tira indicadora de $\mathrm{N}^{-N_{3}}$. $+\mathrm{N}^{-\mathrm{NO}_{2}}{ }^{-}$, e após $60 \mathrm{~s}$ foi efetuada a leitura. O resultado foi obtido por colorimetria, usando-se a escala existente no KQS. O método-padrão para a determinação desse indicador foi a destilação de arraste de vapor em semimicro Kjeldhal, descrita por Tedesco et al. (1995).

\section{Desempenho dos indicadores do KQS na avaliação da qualidade do solo}

Considerando que o estoque do carbono orgânico total (COT), na camada superficial, reproduziu a ordenação teórica de QS proposta (Conceição et al., 2005), essa propriedade foi selecionada para fins de avaliação do desempenho dos indicadores. Para isso, calculou-se o índice de estoque de carbono (IEC) (Blair et al., 1995), de modo que permitisse a análise da melhoria dos sistemas de manejo (variáveis qualitativas) de forma quantitativa.

$$
\mathrm{IEC}=\frac{\mathrm{EST}_{\mathrm{C}} \text { trat. }}{\mathrm{EST}_{\mathrm{C}} \text { ref. }} \times 100
$$

em que $\mathrm{EST}_{\mathrm{C}}$ trat $=$ estoque de COT do tratamento na camada de $0-5 \mathrm{~cm}$; e $\mathrm{EST}_{\mathrm{C}}$ ref = estoque de $\mathrm{COT}$ do $\mathrm{CN}$ na camada de $0-5 \mathrm{~cm}$.

Dessa forma, os valores do IEC foram usados como variável independente, enquanto os valores dos indicadores de QS corresponderam às variáveis dependentes. A correlação entre essas variáveis foi utilizada como critério de desempenho na avaliação da QS induzida pelos sistemas de manejo.

$\mathrm{O}$ estoque do carbono (C) em ambas as áreas experimentais foi determinado por meio da abertura de uma trincheira para determinação da densidade e coleta de amostras de solo, que foram analisadas seguindo o método proposto por Walkley \& Black, descrito por Tedesco et al. (1995). 


\section{Análise estatística}

Os resultados foram submetidos à análise de variância em delineamento completamente casualizado com duas repetições, no PVd arênico, e delineamento de blocos ao acaso com três repetições, no PVd típico. Quando houve significância da análise de variância, as médias dos tratamentos foram comparadas, dentro de cada área experimental, pelo teste de Tukey a $5 \%$. Os valores dos indicadores investigados - segundo os métodos do KQS e os tradicionais utilizados na ciência do solo - foram correlacionados entre si por meio de análise de correlação linear simples. O desempenho dos indicadores na avaliação da QS foi obtido pela correlação desses indicadores com o IEC.

\section{RESULTADOS E DISCUSSÃO}

\section{Correlação entre os métodos do KQS e os tradicionais da ciência do solo}

No quadro 2 são apresentadas as propriedades do solo selecionadas como indicadores de QS e os respectivos coeficientes de correlação entre os resultados obtidos por meio dos métodos do KQS e os tradicionalmente utilizados na ciência do solo. Para a respiração do solo e a estabilidade de agregados (EA), os métodos apresentaram, nas duas áreas experimentais, coeficiente de correlação elevado. Esses resultados concordam com o observado anteriormente por Seybold \& Herrick (2001). O pH foi o indicador que, considerando ambas as áreas, obteve o mais elevado coeficiente de correlação entre os métodos $(\mathrm{r}=0,98)$. Já para a avaliação de $\mathrm{N}-\mathrm{NO}_{3}{ }^{-}+\mathrm{N}^{-} \mathrm{NO}_{2}{ }^{-}$ foi observada maior correlação entre os métodos no PVd típico $(r=0,91)$ do que no PVd arênico $(r=0,69)$. Por sua vez, para a densidade do solo observou-se no $\mathrm{PVd}$ arênico maior correlação $(\mathrm{r}=0,85)$ do que no $\mathrm{PVd}$ típico $(\mathrm{r}=0,50)$.

Entre os indicadores avaliados, a infiltração apresentou o menor coeficiente de correlação entre os métodos, inclusive sem atingir significância estatística, fato verificado em ambas as áreas experimentais. Para o KQS, no PVd arênico, os CVs foram de 15 e $100 \%$ para o método do KQS e o padrão, respectivamente. Já no PVd típico o CV da infiltração, utilizando o KQS, foi de $42 \%$, enquanto nas avaliações

Quadro 2. Respiração do solo ( $\left.\mathrm{CO}_{2}\right)$, estabilidade de agregados em água (EA), pH, teores de nitrato+nitrito $\left(\mathrm{N}_{-} \mathrm{NO}_{3}{ }^{-}+\mathrm{N}_{-} \mathrm{NO}_{2}{ }^{-}\right)$, densidade do solo e infiltração de água nos sistemas de manejo para os dois solos das áreas experimentais avaliadas, determinados pelos métodos do kit de qualidade do solo (KQS) e pelo método-padrão, e coeficiente de correlação entre ambos os métodos

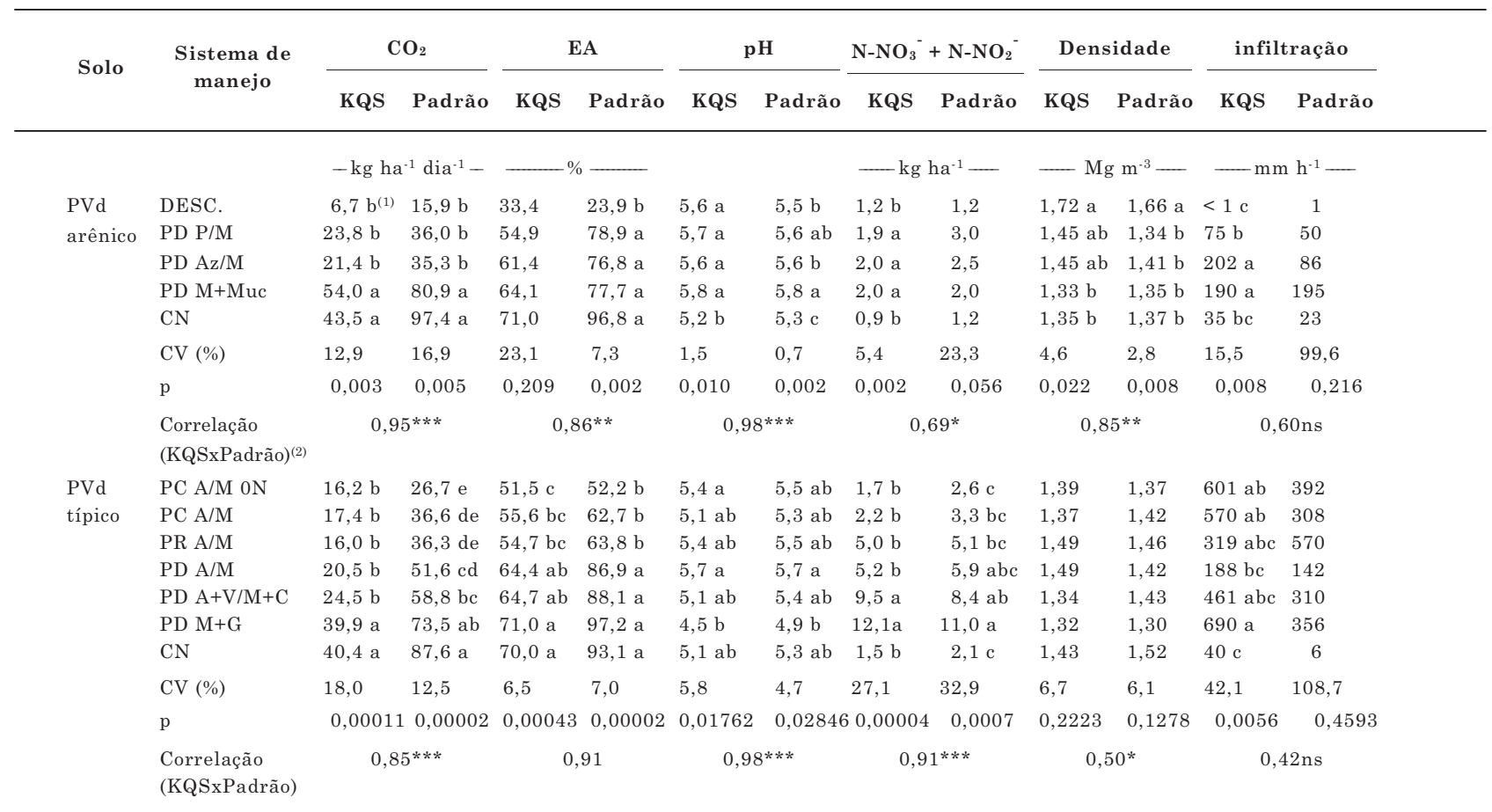

\footnotetext{
(1) Médias seguidas por mesmas letras na coluna e dentro de cada área experimental não diferem pelo teste de Tukey a $5 \%$. ${ }^{(2) * * *}$, **, * e ns: significativos a 0,001, 0,01 e 0,05\% e não-significativo, respectivamente, utilizando todos os dados experimentais (repetições de campo). CV $(\%)=$ coeficiente de variação; DESC. = solo descoberto; $\mathrm{CN}=$ campo natural; $\mathrm{PC}=$ preparo convencional; $\mathrm{PR}=$ preparo reduzido; $\mathrm{PD}=$ plantio direto; $\mathrm{Az}=$ azevém; $\mathrm{P}=$ pousio; $\mathrm{Muc}=$ mucuna; $\mathrm{A}=$ aveia; $\mathrm{M}=$ milho; $\mathrm{V}=$ ervilhaca; $\mathrm{C}=$ caupi $\mathrm{G}=$ guandu; e $0 \mathrm{~N}=$ sem adubação nitrogenada. $\mathrm{PVd}$ arênico = Argissolo Vermelho distrófico arênico; PVd típico = Argissolo Vermelho distrófico típico.
} 
com o método-padrão (duplos anéis concêntricos) ele foi de 109 \% (Quadro 2). Elevados CVs na avaliação da infiltração foram relatados por Sarrantonio et al. (1996) utilizando o KQS, encontrando valores na faixa de 18 a $205 \%$. Levien et al. (2000), utilizando o método dos duplos anéis concêntricos também em Argissolos, obtiveram valores entre 50 e $100 \%$. Portanto, a elevada variabilidade na avaliação deste indicador está associada ao método empregado para investigar a infiltração. Neste trabalho, o número de repetições de infiltração foi de duas por parcela, não sendo suficiente para diminuir a variabilidade observada nas avaliações.

\section{Indicadores da qualidade do solo \\ Respiração do solo}

A respiração do solo avaliada pelo método do KQS variou de ideal a muito baixa no PVd arênico e de ideal a moderadamente baixa no PVd típico (Quadro 2). Nas duas áreas experimentais, o solo sob CN apresentou respiração, avaliada pelo método do KQS, considerada ideal. No PVd arênico, utilizando o mesmo método anterior, o tratamento DESC., sem nenhuma adição de resíduos vegetais por dez anos, resultou em uma respiração classificada como muito baixa, sendo 6,5 vezes inferior à verificada no $C N$. Esse resultado, provavelmente, foi associado à expressiva redução no estoque de COT do tratamento DESC, em relação ao CN (Quadro 3).

Para o PVd típico observou-se que, no sistema de cultura A/M, os sistemas de preparo com mobilização do solo (preparos reduzido e convencional) apresentaram atividade biológica classificada como moderadamente baixa, enquanto o tratamento com mínima mobilização (PD) mostrou respiração média, avaliada pelo método do KQS. No entanto, essas diferenças não foram estatisticamente significativas.

Os tratamentos PD M+Muc e PD M+G apresentaram, em suas respectivas áreas experimentais, os maiores valores de respiração do solo entre os sistemas de culturas avaliados (Quadro 2). Nesses casos, a taxa de respiração (Quadro 1), foi considerada ideal. Destaca-se também nesses tratamentos que a respiração não diferiu estatisticamente do tratamento-referência (CN). Esse resultado positivo está associado às altas adições de $\mathrm{C}$ e $\mathrm{N}$ via resíduos culturais nesses sistemas com sucessão ou consórcio de leguminosas tropicais e gramíneas, quando comparados aos demais sistemas de cultura com predomínio de gramíneas. Assim, quando avaliados pelos métodos do KQS e padrão, respectivamente, o sistema PD M+Muc apresentou incremento de 127 e $125 \%$ na respiração do solo em relação ao PD P/M, no PVd arênico, enquanto no PVd típico o tratamento PD $\mathrm{M}+\mathrm{G}$ proporcionou incremento de 95 e $42 \%$ em relação ao PD A/M.

\section{Estabilidade de agregados (EA)}

Os valores classificados como adequados para EA (Quadro 1), considerando o teor de argila, devem ser
Quadro 3. Estoque de carbono orgânico total (COT) e índice de estoque de carbono (IEC) em dois solos, na camada de 0-5 cm, das áreas experimentais

\begin{tabular}{llcr}
\hline \multirow{2}{*}{ Solo } & Sistema de manejo & COT & IEC (1) \\
& & Mg ha $^{-1}$ & \\
& & 3,21 & 45 \\
PVd & DESC. & 6,76 & 94 \\
arênico & PD P/M & 8,23 & 115 \\
& PD Az/M & 9,42 & 131 \\
& PD M+Muc & 7,18 & 100 \\
& CN & & \\
PVd & PC A/M 0N & 7,27 & 48 \\
típico & PC A/M & 8,47 & 55 \\
& PR A/M & 9,27 & 61 \\
& PD A/M & 10,48 & 69 \\
& PD A+V/M+C & 14,17 & 93 \\
& PD M+G & 16,50 & 108 \\
& CN & 15,28 & 100 \\
\hline
\end{tabular}

(1) $\mathrm{IEC}=\frac{\mathrm{EST}_{\mathrm{C}} \text { trat. }}{\mathrm{EST}_{\mathrm{C}} \text { ref. }} \times 100$, usando o $\mathrm{CN}$ como referência. DESC = solo descoberto; $\mathrm{CN}$ = campo natural; $\mathrm{PC}=$ preparo convencional; $\mathrm{PR}=$ preparo reduzido; $\mathrm{PD}$ - plantio direto; $\mathrm{Az}=$ azevém; $\mathrm{P}=$ pousio; Muc = mucuna $\mathrm{A}=$ aveia $; \mathrm{M}=$ milho; $\mathrm{V}=$ ervilhaca; $\mathrm{C}=$ caupi $\mathrm{G}=$ guandu; e $0 \mathrm{~N}=$ sem adubação nitrogenada. $\mathrm{PVd}$ arênico = Argissolo Vermelho distrófico arênico; PVd típico = Argissolo Vermelho distrófico típico.

superiores a 65 e 70 \% para o PVd arênico e PVd típico, respectivamente. Assim, pelo método do KQS, apenas o tratamento $\mathrm{CN}$, no primeiro solo, e o $\mathrm{PD} \mathrm{M}+\mathrm{G}$ e $\mathrm{CN}$, no segundo, obtiveram EA adequada (Quadro 2). De modo geral, os valores de EA avaliados pelo método do KQS foram inferiores aos do método proposto por Kemper \& Rosenau (1986), considerado neste trabalho como padrão.

No PVd arênico, a EA diferiu entre os tratamentos apenas quando avaliada pelo método-padrão, que apresentou menor CV (7,5 \%) do que o KQS (23\%). A redução de $55 \%$ no estoque de COT no tratamento DESC. em relação ao CN (Quadro 3) refletiu-se em decréscimo de $75 \%$ na EA, avaliada pelo método-padrão (Quadro 2). Dessa forma, a EA observada no tratamento DESC. foi apenas $37 \%$ daquela sugerida como ideal, considerando o teor de argila (Quadro 1). Por sua vez, o sistema PD M+Muc proporcionou incremento de $225 \%$ na EA observada no DESC., pelo método-padrão (Quadro 2). Esse resultado está de acordo com o incremento no estoque de COT, que foi de 193 \% em relação ao DESC. (Quadro 3).

No PVd típico, observou-se que o preparo convencional do solo reduziu a EA quando comparado ao plantio direto (Quadro 2). Assim, foi observado que, independentemente do método investigado, os sistemas de preparo com mobilização (reduzido e convencional) reduziram a EA em relação ao $\mathrm{CN}$, enquanto o $\mathrm{PD}$ não diferiu desse tratamento-referência. No sistema 
de cultura $\mathrm{A} / \mathrm{M}$, o solo sob PD apresentou incrementos de 16 e $39 \%$ na EA, avaliada pelo método do KQS e padrão, respectivamente, em relação ao solo sob PC (Quadro 2). Esse resultado está de acordo com a maior atividade biológica constatada no PD em relação ao PC. Ainda, destaca-se que os preparos convencional e reduzido não diferiram estatisticamente entre si quanto à EA.

As mais elevadas EAs foram verificadas nos tratamentos sob PD com leguminosas estivais e PD $\mathrm{M}+\mathrm{Muc}$, no PVd arênico, e PD M+G, no PVd típico. Esses resultados estão coerentes com o maior estoque de COT (Quadro 3) e a maior atividade biológica, avaliada pela respiração do solo (Quadro 2), verificada nesses tratamentos em relação aos demais, fato que resulta em maior produção de exsudatos microbianos, aumentando a EA.

\section{pH}

Segundo o manual do KQS (USDA-ARS, 1998), o $\mathrm{pH}$ ideal situa-se na faixa de 5,5 a 7,0. O valor superior dessa faixa provavelmente está ajustado aos solos alcalinos de clima temperado. Em condições de solos intemperizados e naturalmente ácidos, como os investigados neste trabalho, valores de $\mathrm{pH}$ acima de 6,5 podem ser indesejáveis devido a elevado investimento no corretivo, menor disponibilidade de alguns micronutrientes, decréscimo na EA, alteração na composição da biota do solo, redução no teor de matéria orgânica e decréscimo no rendimento das principais culturas de grãos.

$\mathrm{O} \mathrm{pH}$, em ambos os solos, foi influenciado pelo histórico de calagem. No PVd arênico, os tratamentos, com exceção do $\mathrm{CN}$, enquadraram-se na faixa de $\mathrm{pH}$ considerada ideal. Já no PVd típico, pelo método do KQS, apenas o solo sob PD A/M está na faixa ideal, enquanto pelo método-padrão os tratamentos $\mathrm{PD} A /$ M, PC A/M ON e PR A/M enquadram-se nessa faixa.

No PVd arênico, observou-se diferença entre os tratamentos que receberam calagem e o CN, que não recebeu esse corretivo, indicando o efeito residual dessa prática. A amplitude de variação do $\mathrm{pH}$ dos tratamentos foi semelhante entre os solos. Assim, a maior diferença no $\mathrm{pH}$ foi de 0,6 unidade, verificada no tratamento $\mathrm{PD} \mathrm{M}+\mathrm{Muc}$ em relação ao $\mathrm{CN}$, avaliado pelo método do KQS. No PVd típico, a maior diferença entre os tratamentos, excluído o PD M+G, também foi de 0,6 unidade, e ela foi verificada entre o solo sob $\mathrm{PD} \mathrm{A} / \mathrm{M}$ e o solo sob $\mathrm{CN}$, avaliada pelo mesmo método anterior. Para o indicador $\mathrm{pH}$, destaca-se que o CN, em ambas as áreas experimentais, devido aos baixos valores, não seria referência de uma condição ideal para o desenvolvimento da maioria das culturas econômicas.

$\mathrm{O}$ tratamento $\mathrm{PD} \mathrm{M}+\mathrm{G}$ apresentou o menor $\mathrm{pH}$ entre todos aqueles investigados, sendo 0,6 e 0,4 unidades inferior ao $\mathrm{CN}$, pelos métodos do KQS e padrão, respectivamente. Essa acidificação do solo no tratamento $\mathrm{PD} M+\mathrm{G}$ pode estar associada à reduzida aplicação de corretivo em relação aos demais tratamentos, aliado, provavelmente, a maiores perdas de $\mathrm{N}$ por lixiviação em relação ao $\mathrm{CN}$. Essa última hipótese é reforçada, uma vez que esse sistema apresentou elevado aporte de $\mathrm{N}$ via resíduos culturais do guandu no outono/inverno, período em que inexistiu uma nova cultura de cobertura para ciclar esse nutriente, predispondo à ocorrência de lixiviação de $\mathrm{NO}_{3}{ }^{-}$(Burle et al., 1997) e, por conseqüência, de cátions básicos (K, Ca e Mg). Ainda, deve-se destacar que este tratamento possui o maior estoque de $\mathrm{C}$ no solo, que pode ser uma fonte de $\mathrm{H}$ ao solo.

\section{Teor de N-NO ${ }_{3}^{-}+\mathrm{N}-\mathrm{NO}_{2}{ }^{-}$}

$\mathrm{O}$ teor de $\mathrm{N}-\mathrm{NO}_{3}{ }^{-}+\mathrm{N}^{-} \mathrm{NO}_{2}{ }^{-}$no solo pode ser um importante indicador de disponibilidade de $\mathrm{N}$ nos sistemas de manejo, além de permitir inferências sobre a intensidade do processo de lixiviação (Evanylo \& McGuinn, 2000). No PVd arênico, o CN e o DESC. apresentaram menores teores desse nutriente na forma mineral do que os observados nos sistemas de produção de milho, avaliados por ambos os métodos (Quadro 2). Entre os sistemas de produção de milho, no entanto, não foi observada diferença estatística. Já no PVd típico o teor desse nutriente no solo mostrouse um indicador sensível à QS induzida pelos sistemas de manejo utilizados. Nesse caso, o teor de $\mathrm{N}^{-\mathrm{NO}_{3}}{ }^{-}+$ $\mathrm{N}-\mathrm{NO}_{2}{ }^{-}$foi incrementado à medida que houve redução na mobilização do solo e aumento da participação das leguminosas nos sistemas de cultura. No plantio direto, o uso de leguminosas nos sistemas PD A + V/ $\mathrm{M}+\mathrm{C}$ e $\mathrm{PD} \mathrm{M}+\mathrm{G}$ apresentou, respectivamente, incrementos de 83 e $133 \%$ no teor de $\mathrm{N}_{-} \mathrm{NO}_{3}{ }^{-}{ }^{+}$ $\mathrm{N}-\mathrm{NO}_{2}{ }^{-}$em relação ao solo sob PD A/M, quando avaliado pelo KQS. Esse resultado é concordante com os incrementos do estoque de $\mathrm{N}$ total do solo, que inclui a forma orgânica e a mineral, e do COT relatados anteriormente por Amado et al. (2001) e Conceição et al. (2005) nesses mesmos tratamentos.

$\mathrm{O}$ PD $\mathrm{M}+\mathrm{G}$ apresentou o maior teor de $\mathrm{N}$ mineral entre os tratamentos avaliados e, em relação ao tratamento-referência, foi aproximadamente oito vezes superior (avaliado pelo método do KQS). Com isso, infere-se que o balanço positivo de $\mathrm{N}$ proporcionado por este sistema (fixação biológica de $\mathrm{N}_{2}$ pela leguminosa + adubação nitrogenada mineral no milho) refletiu-se no aumento da disponibilidade desse nutriente no solo. Por outro lado, no sistema agrícola com balanço negativo de $\mathrm{N}(\mathrm{PC} \mathrm{A} / \mathrm{M} 0 \mathrm{~N})$, onde inexiste adição, com exceção das fontes naturais, e há considerável exportação de $\mathrm{N}$ via grãos, verificou-se decréscimo no teor de $\mathrm{N}-\mathrm{NO}_{3}{ }^{-}+\mathrm{N}-\mathrm{NO}_{2}{ }^{-}$em relação aos sistemas de produção de milho com utilização de leguminosas (PD A+V/M+C e PD M+G) (Quadro 2). Nesse tratamento, o teor de $\mathrm{N}$ mineral foi semelhante ao do $\mathrm{CN}$ e sete vezes inferior, pelo KQS, ao PD M+G. Para o indicador $\mathrm{N}^{-\mathrm{NO}_{3}}{ }^{-}+\mathrm{N}-\mathrm{NO}_{2}{ }^{-}$o solo sob condição natural, em ambas as áreas experimentais, apresentou baixos teores, não representando uma condição ideal para o desenvolvimento de culturas exigentes em N, como o milho. 
A utilização de leguminosas no sistema de produção de milho foi, portanto, eficiente estratégia em incrementar o potencial de suprimento de $\mathrm{N}$ do solo. Esse incremento favorece a nutrição de plantas, estimula a atividade biológica e também a eficiência de armazenamento de C no solo (Silva et al., 2004). Os resultados obtidos neste trabalho reforçam o papel da fixação biológica de $\mathrm{N}_{2}$, proporcionada pelas leguminosas, como estratégia para alcançar sistemas com elevada QS em condições tropicais e subtropicais.

\section{Densidade do solo}

A densidade do solo (Ds) nos tratamentos avaliados variou de ideal a limitante, no PVd arênico, e de ideal a não-limitante, no PVd típico (Quadro 2). Portanto, em nenhum tratamento foi verificada densidade classificada como restritiva, a qual corresponde a valores de Ds superiores a 1,80 e $1,75 \mathrm{Mg} \mathrm{m}^{-3}$ para o PVd arênico e típico, respectivamente (USDA-ARS, 1998).

Apenas no PVd arênico houve diferença estatística entre os tratamentos, embora neste solo todos os tratamentos tenham apresentado Ds classificada como ideal, exceto o DESC. Já no PVd típico, a Ds ideal, avaliada pelo KQS, foi observada nos tratamentos sob preparo convencional (PC A/M 0N e PC A/M) e nos tratamentos sob $\mathrm{PD}$ que utilizaram leguminosas como culturas de cobertura (PD A+V/M+C e PD M+G).

Considerando ambos os solos, os menores valores de Ds no PD ocorreram nos tratamentos PD M+Muc e PD M+G. A influência positiva da inclusão de leguminosas tropicais nesse indicador está, provavelmente, relacionada a dois efeitos principais. Primeiramente, o incremento no estoque de COT verificado nestes tratamentos (Conceição et al., 2005). Thomaz et al. (1997) constataram redução na Ds de, aproximadamente, $0,13 \mathrm{Mg} \mathrm{m}^{-3}$ para cada unidade de percentagem de incremento no estoque de COT, para o intervalo de 1 a $4 \%$ de COT. Esse resultado ainda pode estar associado ao incremento da agregação do solo, em parte resultante do aumento no estoque de COT. Em segundo lugar, o sistema radicular pivotante das leguminosas pode, em algumas situações, se desenvolver mesmo em camadas adensadas e, conseqüentemente, manter a densidade em nível favorável ao desenvolvimento vegetal (Cubilla et al., 2002).

\section{Infiltração de água}

A infiltração, avaliada pelo método do KQS, variou de muita lenta $\left(<1 \mathrm{~mm} \mathrm{~h}^{-1}\right.$ no DESC.) a rápida $\left(202 \mathrm{~mm} \mathrm{~h}^{-1}\right.$ no PD Az/M) no PVd arênico e de moderada $\left(40 \mathrm{~mm} \mathrm{~h}^{-1}\right.$ no $\left.\mathrm{CN}\right)$ a muito rápida (690 $\mathrm{mm} \mathrm{h}^{-1}$ no PD M+G) no PVd típico (Quadro 1).

No PVd arênico, a utilização de culturas de cobertura (azevém+ervilhaca e mucuna) no sistema de produção de milho favoreceu a infiltração em relação ao tratamento com ausência de culturas de cobertura (pousio/milho). Nos tratamentos com culturas de cobertura a infiltração foi classificada como rápida, enquanto com pousio de inverno foi moderadamente rápida. Essa diferença na infiltração somente foi estatisticamente significativa para os resultados obtidos pelo KQS, que apresentaram menor CV do que o método-padrão.

No PVd típico, a intensidade e diversificação do sistema de cultura também favoreceu a infiltração. Assim, o tratamento PD A+V/M+C (quatro culturas $a^{-1}$ ) apresentou incrementos de 145 e $118 \%$ na infiltração avaliada pelos métodos do KQS e padrão, respectivamente, em relação à verificada no $\mathrm{PD} A / \mathrm{M}$ (duas culturas ano-1). A maior quantidade de raízes nos sistemas de policulturas pode explicar parcialmente esses resultados.

A infiltração foi classificada como muito rápida nos tratamentos PC A/M 0N, PC A/M e PD M+G, quando avaliada pelo KQS (Quadro 1). Por outro lado, no PD, com os sistemas $\mathrm{A} / \mathrm{M}$ e $\mathrm{A}+\mathrm{V} / \mathrm{M}+\mathrm{C}$, e no $\mathrm{PR} \mathrm{A} / \mathrm{M}$ a infiltração foi rápida. Deve-se destacar que esses tratamentos não diferiram estatisticamente entre si.

$\mathrm{O}$ uso de leguminosas estivais, como cultura de cobertura no sistema plantio direto, foi eficiente estratégia para incrementar a infiltração em ambos os solos. No PVd arênico, o PD M+Muc aumentou a infiltração em 153 e $290 \%$ quando avaliada pelo método do KQS e padrão, respectivamente, em relação ao PD P/M (Quadro 2). Já o PD M+G, no PVd típico, aumentou a infiltração em 267 e $151 \%$ pelo método do KQS e padrão, respectivamente, quando comparado ao PD A/M. No entanto, ressalta-se que esses tratamentos só diferiram quanto à infiltração quando avaliados pelo KQS. O efeito positivo das leguminosas no sistema PD sobre a taxa de infiltração pode estar associado ao incremento dos poros condutores de água, conforme anteriormente relatado por Silva et al. (2004).

$\mathrm{O} \mathrm{CN}$, em ambas as áreas experimentais, apresentou infiltração classificada como moderada, exceção no PVd típico, que foi lenta, quando determinada pelo método-padrão (Quadro 1). Portanto, pelos métodos de avaliação da infiltração utilizados neste trabalho, a condição original da área $(\mathrm{CN})$ não representou uma situação ideal a ser reproduzida nos sistemas de produção agrícola. A limitada infiltração observada sob $\mathrm{CN}$ pode estar relacionada ao denso sistema radicular presente principalmente na camada superficial de solo e à elevada quantidade de mantilho. Nessas condições de superfície, o CN pode apresentar elevadas perdas de água por enxurrada, conforme observado por Debarba \& Amado (1997). Os resultados apresentados neste trabalho evidenciam que os sistemas de cultura diversificados, quando associados ao $\mathrm{PD}$ e adotados por longo período de tempo, podem inclusive melhorar a permeabilidade original da área.

A menor infiltração verificada entre os tratamentos ocorreu no solo descoberto, a qual foi classificada como muito lenta. Nesse tratamento, provavelmente a obstrução da porosidade superficial, conseqüência do impacto direto das gotas de chuva, aliada à degradação da qualidade física na camada superficial do solo 
tenham sido determinantes na redução da infiltração. Ainda, destaca-se que, devido à composição textural, com significativa percentagem de silte, o solo PVd arênico, quando mantido descoberto, forma crostas superficiais de elevada coesão, que restringem severamente a permeabilidade.

\section{Eficiência dos indicadores do KQS na avaliação da qualidade do solo}

Na figura 1 (a,b) é apresentada a ordenação teórica de QS com base nas adições de $\mathrm{C}$ e $\mathrm{N}$ e na intensidade de revolvimento do solo. Da maneira apresentada, a melhoria de manejo do solo foi hierarquizada de forma qualitativa. Entretanto, com o objetivo de transformar a melhoria de manejo numa variável quantitativa, esta foi classificada pelo IEC (Figura $1 \mathrm{c}, \mathrm{d}$ ). A justificativa para esse pressuposto é o fato de o estoque de COT ter sido muito sensível às alterações de manejo (Conceição et al., 2005). Portanto, a eficiência dos indicadores em discriminar as alterações na QS induzidas pelos sistemas de manejo foi avaliada pela correlação destes com o IEC (Quadro 4).

No PVd arênico, somente a densidade do solo e a estabilidade de agregados mostraram correlações significativas com o índice IEC. Já no PVd típico, os indicadores significativos foram: respiração do solo, estabilidade de agregados e teor de $\mathrm{N}-\mathrm{NO}_{3}{ }^{-}+\mathrm{N}-\mathrm{NO}_{2}{ }^{-}$
(Quadro 4). O pH, nas condições deste trabalho, foi um indicador mais influenciado pelo histórico de práticas de manejo utilizadas, como calagem, adubação e sistema de cultura, do que propriamente pela QS

Quadro 4. Correlação dos indicadores avaliados pelo kit de qualidade do solo com o índice de estoque de carbono para os Argissolos das áreas experimentais avaliadas

\begin{tabular}{|c|c|c|c|c|}
\hline \multirow{3}{*}{ Propriedade } & \multicolumn{4}{|c|}{$\begin{array}{c}\text { Índice de estoque } \\
\text { de carbono }\end{array}$} \\
\hline & \multicolumn{2}{|c|}{ PVd arênico } & \multicolumn{2}{|c|}{ PVd típico } \\
\hline & $\mathbf{r}$ & $\mathbf{p}^{(1)}$ & $\mathbf{r}$ & $\mathbf{p}$ \\
\hline Estabilidade de agregados & 0,99 & * & 0,93 & $* *$ \\
\hline Respiração do solo & 0,87 & $\mathrm{~ns}$ & 0,92 & $* *$ \\
\hline Densidade do solo & $-0,97$ & * & $-0,54$ & $\mathrm{~ns}$ \\
\hline Infiltração & 0,94 & $\mathrm{~ns}$ & 0,24 & $\mathrm{~ns}$ \\
\hline $\mathrm{pH}$ & 0,63 & $\mathrm{~ns}$ & $-0,71$ & $\mathrm{~ns}$ \\
\hline Nitrato+nitrito & 0,93 & $\mathrm{~ns}$ & 0,99 & $* * *$ \\
\hline
\end{tabular}

(1) $* * *, * * *$ e ns: significativos a $0,001,0,01$ e $0,05 \%$ e nãosignificativo, respectivamente.

PVd arênico $=$ Argissolo Vermelho distrófico arênico. PVd típico = Argissolo Vermelho distrófico típico.
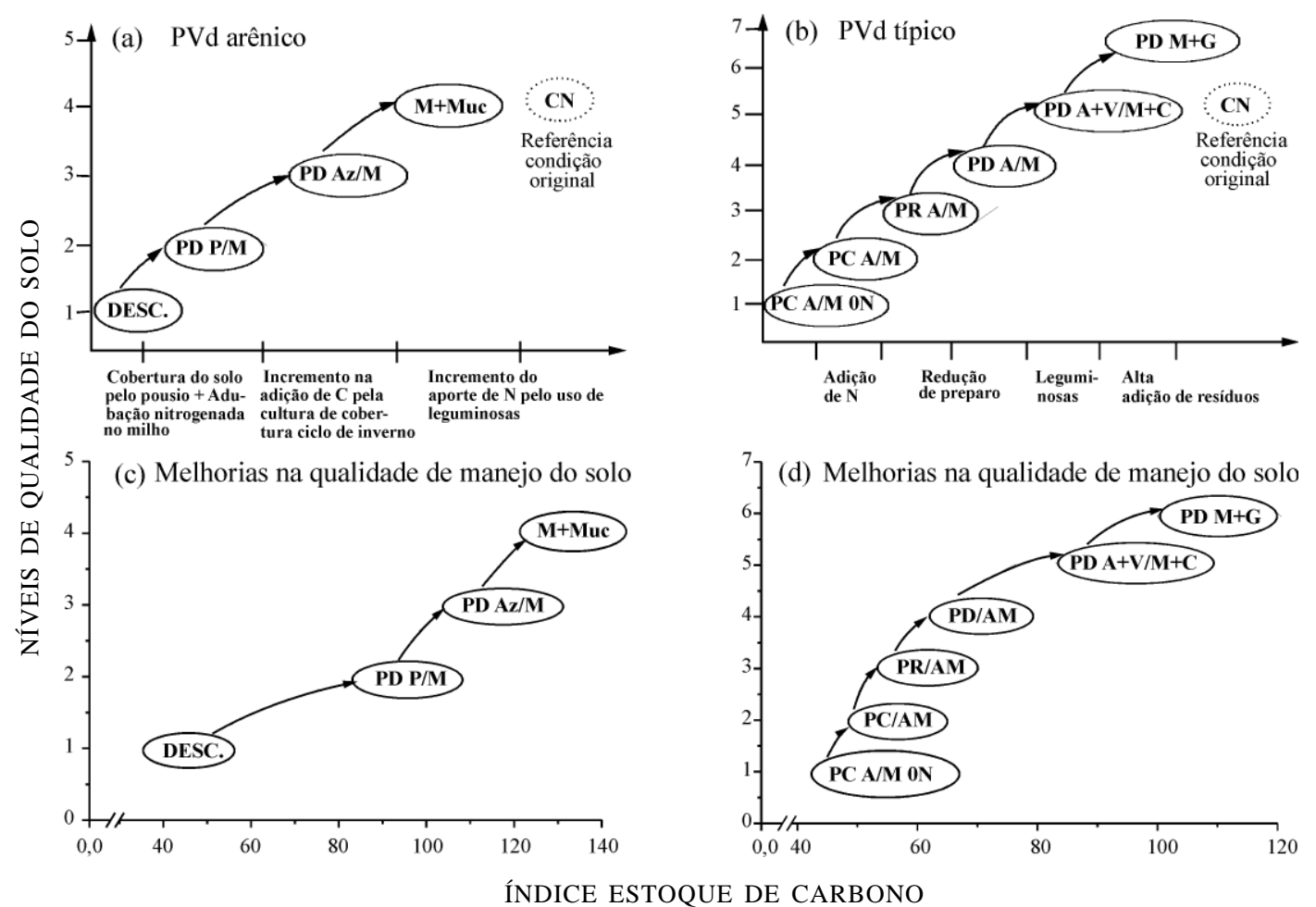

Figura 1. Sistema de organização teórico proposto para a ordenação da qualidade do solo segundo as melhorias de manejo (a, b) e a relação do índice estoque de carbono (IEC) com os mesmos níveis de qualidade do solo $(\mathrm{c}, \mathrm{d})$. DESC. = solo descoberto; $\mathrm{CN}=$ campo natural $; \mathrm{PC}=$ preparo convencional; $\mathrm{PR}=$ preparo reduzido; $\mathrm{PD}=$ plantio direto; $\mathrm{Az}=$ azevém; $\mathrm{P}=$ pousio; $\mathrm{Muc}=$ mucuna; $\mathrm{A}=$ aveia; $\mathrm{M}=\mathrm{milho} ; \mathrm{V}=$ ervilhaca; $\mathrm{C}=$ caupi; $\mathrm{G}=$ guandu; $\mathrm{eN}=$ sem adubação nitrogenada. $\mathrm{PVd}$ arênico = Argissolo Vermelho distrófico arênico; PVd típico = Argissolo Vermelho distrófico típico. 
induzida pelos tratamentos. Portanto, não foi um indicador eficiente em discriminar a qualidade de sistemas de manejo.

Os três indicadores selecionados (Figura 2), independentemente do método investigado, reproduziram eficientemente a hierarquia teórica de QS proposta, com exceção do teor de $\mathrm{N}-\mathrm{NO}_{3}{ }^{-}+\mathrm{N}^{-} \mathrm{NO}_{2}{ }^{-}$ no PVd arênico.

A amplitude de variação entre os tratamentos extremos foi utilizada para acessar o impacto de sistemas de manejo conservacionistas na melhoria da QS. Assim, no PVd arênico, no tratamento PD M+Muc (melhor tratamento) verificaram-se, para estabilidade de agregados, respiração do solo e nitrato + nitrito, incrementos, respectivamente, de 92, 706 e $66 \%$ em relação ao DESC. (pior tratamento), avaliados pelo método do KQS, enquanto no PVd típico os incrementos para esses mesmos indicadores foram de 38,146 e $612 \%$, respectivamente, na comparação do $\mathrm{PD} \mathrm{M}+\mathrm{G}$ com $\mathrm{PC} \mathrm{A} / \mathrm{M} 0 \mathrm{~N}$.

Interessante registrar que, para esses indicadores, o solo sob CN apresentou valores semelhantes em ambas as áreas experimentais (Quadro 2). Pelo método do KQS, os valores obtidos para estabilidade e respiração do solo com o sistema PD M+Muc, no PVd arênico, também foram comparáveis aos verificados no PD A+V/M+C e PD M+G, no PVd típico.

$\mathrm{O} \mathrm{KQS}$, de forma geral, mostrou-se uma ferramenta prática e eficiente para avaliar a QS. Os custos do equipamento são compatíveis com as análises previstas; destaca-se que o maior custo neste trabalho foi a aquisição dos tubos para avaliação da respiração do solo necessário para as repetições.
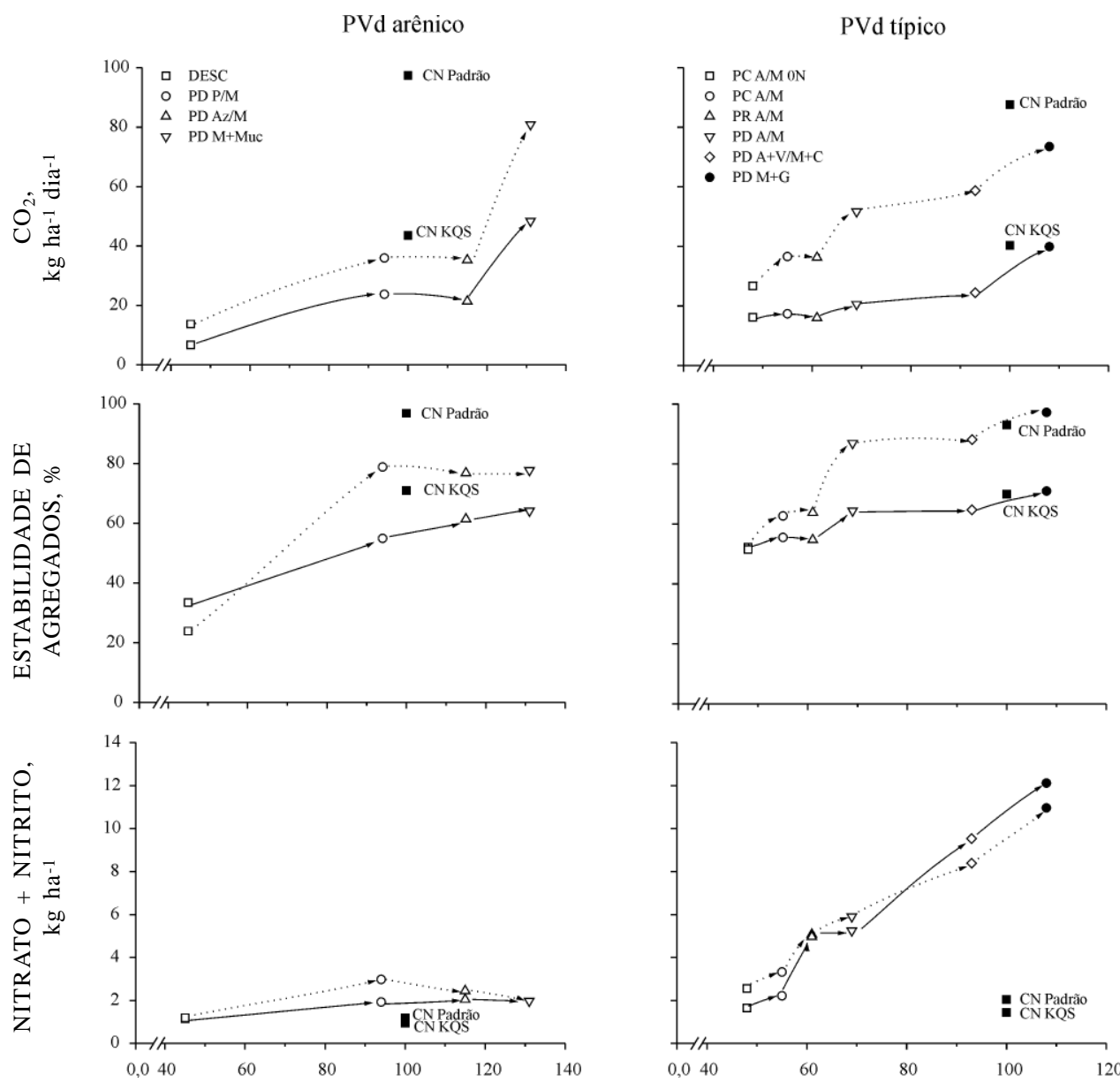

ÍNDICE ESTOQUE DE CARBONO

Figura 2. Relação entre o Índice de Estoque de Carbono (IEC) e os indicadores respiração do solo $\left(\mathrm{CO}_{2}\right)$, estabilidade de agregados em água e nitrato+nitrito, avaliados pelos métodos padrão (linha pontilhada) e do kit de qualidade do solo (linha cheia). DESC. = solo descoberto; $\mathrm{CN}=$ campo natural; $\mathrm{PC}=$ preparo convencional $\mathrm{PR}=$ preparo reduzido; $\mathrm{PD}=$ plantio direto; $\mathrm{Az}=$ azevém; $\mathrm{P}=$ pousio; Muc $=$ mucuna; $\mathrm{A}=$ aveia; $\mathrm{M}=$ milho; $\mathrm{V}=$ ervilhaca; $\mathrm{C}=$ caupi; $\mathrm{G}=$ guandu $\mathrm{e} \mathbf{0 N}=$ sem adubação nitrogenada. $\mathrm{PVd}$ arênico = Argissolo Vermelho distrófico arênico; PVd típico = Argissolo Vermelho distrófico típico. 


\section{CONCLUSÕES}

1. Os métodos utilizados no kit de qualidade do solo apresentaram correlação significativa com os tradicionalmente usados na ciência do solo, com exceção da infiltração de água.

2. A estabilidade de agregados foi o indicador que melhor reproduziu os níveis de hierarquia da qualidade do solo induzidos por melhorias nas práticas de manejo, em ambos os Argissolos investigados.

3. Os níveis mais altos de qualidade do solo foram alcançados sob sistema plantio direto associado a sistemas de cultura diversificados, com destaque para os que incluíam leguminosas tropicais, que aportaram elevadas quantidades de $\mathrm{C}$ e $\mathrm{N}$ via resíduos culturais.

4. O campo nativo apresentou condição ideal para os indicadores estabilidade de agregados, atividade biológica e densidade do solo, porém não para a infiltração, o $\mathrm{pH}$ e o teor de $\mathrm{N}-\mathrm{NO}_{3}{ }^{-}+\mathrm{N}-\mathrm{NO}_{2}{ }^{-}$.

5. O kit de qualidade de solo foi uma ferramenta de fácil manuseio, rápida e sensível às modificações induzidas pelos sistemas de manejo. No entanto, a eficiência de alguns de seus indicadores deve ser confirmada para um conjunto maior de classes de solo.

\section{LITERATURA CITADA}

AMADO, T.J.C; BAYER, C.; ELTZ, F.L.F. \& BRUM, A.C.R Potencial de culturas de cobertura em acumular carbono e nitrogênio no solo no plantio direto e a melhoria da qualidade ambiental. R. Bras. Ci. Solo, 25:189-197, 2001.

ANDERSON, J.P.E. Soil respiration. In: KLUTE, A., ed. Methods of soil analysis. Physical and mineralogical methods. Part 1. 2.ed. Madison, American Society of Agronomy, Soil Science Society of America, 1986. p. 831-872.

ARSHAD, M.A. \& MARTIN, S. Identifying critical limits for soil quality indicators in agro-ecosystems. Agric. Ecos. Environ., 88:153-160, 2002.

BLAIR, J. B.; LEFROY, R. D. B. \& LISLE, L. Soil carbon fractions based on their degree of oxidation, and the development of a carbon management index for agricultural systems. Aust. J. Agric. Res., 46:1459-1466, 1995.

BOUWER, H. Intake rate: Cylinder infiltrometer. In: KLUTE, A., ed. Methods of soil analysis. Physical and mineralogical methods. Part 1. 2.ed Madison, American Society of Agronomy, Soil Science Society of America, 1986. p.825844 .

BURLE, M.L.; MIELNICZUK, J. \& FOCCHI, S. Effect of cropping systems on soil chemical characteristics, with emphasis on soil acidification. Plant Soil, 190:309-316, 1997.

COMISSÃO DE FERTILIDADE DO SOLO-CFRS/SC. Recomendações de adubação e calagem para o Estado do Rio Grande do Sul e Santa Catarina. 3.ed. Passo Fundo, SBCS-Núcleo Regional Sul, Embrapa/CNPT, 1995. 223p.
CONCEIÇÃO, P.C.; AMADO, T.J.C.; MIELNICZUK, J. \& SPAGNOLLO, E. Qualidade do solo em sistemas de manejo avaliada pela dinâmica da matéria orgânica e atributos relacionados. R. Bras. Ci. Solo, 29:777-788, 2005.

CUBILLA, M.; REINERT, D.J.; AITA, C. \& REICHERT, J.M. Plantas de cobertura do solo: Uma alternativa para aliviar a compactação em sistema plantio direto. R. Plantio Direto, 71:29-32, 2002.

DEBARBA, L. \& AMADO, T.J.C. Desenvolvimento de sistemas de produção de milho no sul do Brasil com características de sustentabilidade. R. Bras. Ci. Solo, 21:473-480, 1997.

DITZLER, C.A. \& TUGEL, A.J. Soil quality field tools: Experience of USDA-NRCS Soil Quality Institute. Agron. J., 94:33-38, 2002.

DORAN, J.W. \& PARKIN, T.B. Defining and assessing soil quality. In: DORAN, J.W.; COLEMAN, D.C.; BEZDICEK, D.F. \& STEWART, B.A., eds. Defining soil quality for a sustainable environment. Madison, Soil Science Society of America, 1994. p.3-22. (Publication Number, 35)

EMPRESA BRASILEIRA DE PESQUISA AGROPECUÁRIA EMBRAPA. Centro Nacional de Pesquisa Agropecuária de Solos. Sistema brasileiro de classificação de solos. Rio de Janeiro, 1999. 412p.

EMPRESA BRASILEIRA DE PESQUISA AGROPECUÁRIA EMBRAPA. Centro Nacional de Pesquisa Agropecuária de Solos. Manual de métodos de análise de solo/Centro Nacional de pesquisa de solos. 2.ed. Rio de Janeiro, 1997. $212 \mathrm{p}$.

EVANYLO, G. \& McGUINN, R. Agricultural management practices and soil quality: Measuring, assessing, and comparing laboratory and field test kit indicators of soil quality attributes. Disponível em: <http:/www. ext.vt.edu/ pubs/compost/45-400/452-400. acesso em 12 fev. 2007.

KEMPER, W.D. \& ROSENAU, R.C. Aggregate stability and size distribution. In: KLUTE, A., ed. Methods of soil analysis. Physical and mineralogical methods. Part 1. 2.ed. Madison, American Society of Agronomy, Soil Science Society of America, 1986. p.425-442.

KLUTE, A. Methods of soil analysis. Physical and mineralogical methods. Part 1. 2 ed. Madison, American Society of Agronomy, Soil Science Society of America, 1986. 1188p.

LEVIEN, R.; JONG van LIER, Q. \& ALVES, A.G.C. Influence of surface crust on water infiltration rates measured by a rotating-boom rainfall simulator and a double-cylinder device. R. Bras. Ci. Solo, 24:479-486, 2000.

LIEBIG, M.A.; DORAN, J.W. \& GARNER, J.C. Evaluation of a field test kit for measuring selected soil quality indicators. Agron. J., 88:683-686, 1996.

LOVATO, T. Dinâmica do carbono e do nitrogênio do solo afetada por preparos do solo, sistemas de cultura e adubo nitrogenado. Porto Alegre, Universidade Federal do Rio Grande do Sul, 2001. 132 p. (Tese de Doutorado)

MIELNICZUK, J.; BAYER, C.; VEZZANI, F.M.; LOVATO, T.; FERNANDES, F.F. \& DEBARBA, L. Manejo de solo e culturas e sua relação com os estoques de carbono e nitrogênio do solo. In: CURI, N.; MARQUES, J.J.; GUILHERME, L.R.G.; LIMA, J.M.; LOPES, A.S. \& ALVAREZ.V., V.H., eds. Tópicos em ciência do solo. Viçosa, MG, Sociedade Brasileira de Ciência do Solo, 2003. v.3. p.209-248. 
MORENO, J.A. Clima do Rio Grande do Sul. Porto Alegre, Secretaria da Agricultura, Diretoria de Terras e Colonização, Seção de Geografia, 1961. 46p.

MOTTA, A.C.V.; REEVES, D.W. \& TOUCHTON, J.T. Longterm tillage system effects on chemical soil quality indicators in the southeastern coastal plain. In: ANNUAL SOUTHERN CONSERVATION TILLAGE CONFERENCE FOR SUSTAINABLE AGRICULTURE, 23.; Lousiana, 2000. Proceedings. "Agricultural Water Quality and Quantity: Issues for the 21st Century”. Louisiana, 2000. p.114-120.

PAGE, A.L.; MILLER, E.H. \& KEENEY, D.R., eds. Methods of soil analysis. Part 2 -Chemical and microbiological properties. 2.ed. Madison, American Society of Agronomy, Soil Science Society of America, 1982. 1159p.

PROGRAMA MULTIINSTITUCIONAL DE DIFUSÃO DE TECNOLOGIA EM MILHO DO RIO GRANDE DO SUL. Recomendações técnicas para a cultura do milho no estado do Rio Grande do Sul. Porto Alegre, FEPAGRO; EMATER/ RS; FECOAGRO/RS, 1999. 146p. (Boletim Técnico, 6)

SARRANTONIO, M.; DORAN, J.W.; LIEBIG, M.A. \& HALVORSON, J.J. On-farm assessment of soil quality and health. In: DORAN, J.W. \& JONES, A.J., eds. Methods for assessing soil quality. Madison, Soil Science Society of America, 1996. p.83-105 (Special Publication, 49)
SEYBOLD, C.A. \& HERRICK, J.E. Aggregates stability kit for soil quality assessment. Catena, 44:37-45, 2001.

SILVA, I.R.; NOVAIS, R.F.; BARROS, N.F. \& SILVA, E.F. Manejo de resíduos e matéria orgânica do solo em plantações de eucalipto: Uma questão estratégica para a manutenção da sustentabilidade: A ciência do solo e o seqüestro de $\mathrm{CO}_{2}$. B.Inf. SBCS, 29:10-20, 2004.

SILVA, S.L.; REICHERT, J.M. \& REINERT, D.J. Escarificação mecânica e biológica para a redução da compactação em Argissolo franco-arenoso sob plantio direto. R. Bras. Ci. Solo, 28:519-531, 2004.

TEDESCO, M. J.; GIANELLO, C.; BISSANI, C.A.; BOHNEN, H. \& VOLKWEISS, S.J. Análises de solo, plantas e outros materiais. Porto Alegre, Universidade Federal do Rio Grande do Sul, 1995. 174p. (Boletim Técnico, 5)

THOMAZ, G.W.; SOROKINA, M. \& ADAMS, D.S. La siembra directa y la calidad del suelo. In: CONGRESO NACIONAL DE AAPRESID, 5., Mar del Plata, 1997. Resumos. Mar del Plata, 1997. p. 201-229.

USDA-ARS. Soil quality test kit guide. Washington, Soil Quality Institute, 1998. $82 \mathrm{p}$.

VEZZANI, F.M. Qualidade do sistema solo na produção agrícola. Porto Alegre, Universidade Federal do Rio Grande do Sul, 2001. 184 p. (Tese de Doutorado) 